\title{
The Place of Sustainability in Architectural Education: Discussion and Suggestions
}

\author{
By Basak Gucyeter ${ }^{*}$
}

\begin{abstract}
Architecture is a unique discipline that facilitates spatial solutions for human needs and has a fundamental responsibility to ensure a sustainable built environment. Signified as a combination of technology and design, architecture is strongly related to diverse disciplines such as sociology, psychology and physics. Furthermore, the contextual political and economic conditions are influential on architectural practice. Within this multi-faceted nature, it is necessary to recognize architecture as a combination of creativity, scientific knowledge and technological innovation. Essentially a contested concept with a multitude of approaches and sustainability is considered vital for architecture discipline. Nonetheless it is either underestimated or dominates design approaches with technological superiority. Similarly, teaching sustainability in architectural education is by agreement defined essential; however, the majority of curricula are inefficient in integrating sustainability with a comprehensive approach. However, in order to envision a sustainable built environment, the architecture curriculum has to cover a basic understanding of the link between sustainability, technology and design. Therefore, built upon the arguments in literature, this theoretical paper discusses the means to underpin concepts of sustainability within a responsive architecture curriculum. In a constantly evolving architectural practice, the need for a mind-shift for educators, students and professionals regarding sustainability approaches is an essential constituent to provide holistic design approaches. In order to achieve such progress, revisions in the architecture curricula that establish a balanced comprehension between creativity and integration of sustainability approaches are of utmost importance.
\end{abstract}

\section{Introduction}

Sustainability is essentially a contested concept ${ }^{1}$ and a prominent statement in vocalizing our concerns about the future of the world, even the subject matter diverges from economics to urban studies, energy policies to politics, healthcare to transportation. In this vast pool of diverse discourses, the focal issue is common: discussing what sustainability is and how it should be defined, emphasized or addressed as a potential objective. Despite this common focus, a limited path has been paved towards a sustainable future

\footnotetext{
* Assistant Professor, Eskisehir Osmangazi University, Turkey.

1. Simon Guy and Graham Farmer, "Reinterpreting Sustainable Architecture: The Place of Technology," Journal of Architectural Education 54-3 (2001): 140-148, doi: http://doi.acm.org/10.1162/10464880152632451.
} 
since the Brundtland Report. ${ }^{2,3}$ The reason for such a delay in progress is comprehensible, when it is realized that the required depth of the concept is not met extensively. Contrastingly, in discourses, sustainability is used as an attractive instrument with a 'supernatural' problem solving ability, without realizing the diversity of the constituent approaches.

Often confused with the word 'conservation', ${ }^{4}$ sustainability is usually underestimated and rendered to a certain contemporary 'motto', used as a denotation 'to preserve and maintain the current status'. Moreover, maintaining the status quo ${ }^{6}$ is a key determinant in politics, thus sustainability impetuously becomes a political statement, emptied into pure symbolism, and represents an 'awareness-like' attitude among stakeholders. Nonetheless, the question that needs to be answered is whether the nature of sustainability is that tolerant to be manipulated with such attenuation. The problem either stems from the ambiguous nature of the concept, or is induced by the complexity of endeavors required to comprehend the concept holistically and act upon it appropriately. $^{7}$ Whichever the reason is, a prosperous notion with multidimensional and multi-disciplinary aspects becomes rendered down to a word attributed with certain alien connotations, to a symbol often used as a prefix for issues involving development disguised in an environmentally sensitive manner, and it is not grasped within a holistic approach. Instead, it is pragmatically applied with its most palpable characteristics.

Given the discussions on how sustainability is perceived and translated into discourse as a tool for contemporary delivery of environmental sensitivity, the architectural education as well, requires a closer look for integrating the concept in its curriculum. Similar to the relationship between the perception of sustainability and its articulated form in other disciplines, architectural education as well fails to address the concept in a holistic manner. ${ }^{8}$ Therefore, it is necessary to scrutinize the place of sustainable approaches and

2. WCED, World Commission on Environment and Development, Our Common Future Brundtland Report. United Nations Report (Oxford University Press, 1987).

3. Paul E. Murray and Alison J. Cotgrave, "Sustainability literacy: the future paradigm for construction education?" Structural Survey 25-1 (2007): 7-23, doi: http://doi.acm.org/10.1108 /02630800710740949.

4. J. Baird Callicott and Karen Mumford, "Ecological Sustainability as a Conservation Concept," Conservation Biology 11-1 (1997): 32-40, doi: http://doi.acm.org/10.1046/j.15231739.1997.95468.x.

5. Jaap G. Rozema et al., "An investigation of environmental and sustainability discourses associated with the substantive purposes of environmental assessment," Environmental Impact Assessment Review 33 (2012): 80-90, doi: http://bit.ly/1TzWvxx.

6. Nora Räthzel and David Uzzell, "Transformative environmental education: a collective rehearsal for reality," Environmental Education Research 15-3 (2009): 263-277, doi: http://dx.doi.org/10.1080/13504620802567015.

7. Sergio Altomonte, Peter Rutherford, and Robin Wilson, "Mapping the Way Forward: Education for Sustainability in Architecture and Urban Design," Corporate Social Responsibility and Environmental Management 21 (2014): 143-154, doi: http://doi.acm. org/10.1002/csr.1311.

8. Sergio Altomonte, "Environmental Education for Sustainable Architecture," Review of European Studies 1-2 (2009): 12-21, doi: http://bit.ly/1Q54ehp. 
technologies in architectural education, since it provides the knowledge basis for the profession. ${ }^{9,10,11}$

The attempt to ensure a sustainable built environment requires well-trained professionals, ${ }^{12}$ especially architects. Thus, an architecture curriculum is of high importance in supporting professional decisions in architectural practice. However, curricula in the majority of schools lack the thorough integration of sustainability within architectural education. ${ }^{13}$ This paper, therefore, focuses on investigating the place of sustainability in architectural education, with a theoretical discussion that aims to reveal how sustainability is perceived in architecture practice and education and a responsive curriculum suggestion that asserts an approach to underpin how concepts of sustainability could holistically be introduced within curricula. Critical exploration of the paper aims to address the knowledge gap and implications related to sustainability education in architecture. Hence, it would be possible to assert an approach. ${ }^{14}$

\section{The Place of Sustainability in Architecture}

Sustainability is one of the few concepts, on which discourses and debates are vast, yet repercussions of these debates in disciplines such as architecture are biased and severely gapped in addressing its thorough nature. The phenomenon originates, either due to the broad and open-to-discussion nature of sustainability, or the lack of interdisciplinary knowledge to comprehend the aspects within sustainability. In order to reinforce this argument, it would be significant to focus on how sustainability is perceived within architectural practice.

Brundtland Report ${ }^{15}$ elaborates the sustainable development concept with a commonly quoted definition: "Development that meets the needs of the present without compromising the ability of future generations to meet their own needs." This definition practically became the catch phrase for the majority of the research, debates, and reports that aim to integrate sustainability within the discourse of a discipline. Hence, the 'symbolized word' offered an immaculate public understanding to disseminate the concept further, yet with certain deviation from what sustainability actually covers. Back in 1987, this

9. Ibid.

10. Guy and Farmer, "Reinterpreting Sustainable Architecture: The Place of Technology," 140-148.

11. Philip Jennings, "New directions in renewable energy education," Renewable Energy 34 (2009): 435-439, doi: http://doi.acm.org/10.1016/j.renene.2008.05.005.

12. Murray and Cotgrave, "Sustainability literacy: the future paradigm for construction education?" 7-23.

13. Alexander Lidgren, Hakan Rodhe and Don Huisingh, "A systemic approach to incorporate sustainability into university courses and curricula," Journal of Cleaner Production 14 (2006): 797-809, doi: http://bit.ly/1PRLfZG.

14. Torsten Masseck, "Teaching Sustainability through Living Labs in Architecture: The case study of the UPC-LOW3 prototype solar house," pres. at The Engineering Education for Sustainable Development (Cambridge, UK, 2013).

15. WCED, Brundtland Report. 
definition, without a doubt has provided a precious clue on how humans should relate with the environment and its resources, yet its strength is exploited as a stereotype definition today. ${ }^{16}$

In architecture, sustainability is denoted with terms such as 'green', 'ecological', 'environmentally sensitive', and 'energy-efficient', since the discipline is a combination of artistic, ecological, social, political and ethical concerns. ${ }^{17}$ However, none of these conceptual terms essentially correspond to the multi-dimensional nature of sustainability. Architecture, considered as the art and technology forming the built environment, becomes the perfectly appropriate medium to propagate sustainability as a prefix to rationalize technological innovation, rather than incorporating its variety of discourses as design decisions. In addition, policy makers, aware of the opportunity to exploit the quantifiable aspects sustainability offers, invent a wide range of control mechanisms called the building rating systems, generally tailored to economic policies. Thus, rating systems solely offer checklists to evaluate buildings within an array, from sustainable to unsustainable.

In today's competitive economic and political environment buildings are often regarded as commodities, and the act of 'building' is perceived as a manifestation of political power and governing. Thus, approaches such as establishing control systems, providing energy ratings suddenly become essential to legitimize the adverse effects of the rapidly growing built environment. Procedures that determine their 'sustainable' and 'environmental' characteristics promise 'accredited' buildings with an environmentally safer, sensitive, and less harmful operation. However, it is as well possible to assert that the offered market transformations and emblematic values in the building sector results with more profit. On the other hand, research on the building performance gap points out conflicting outcomes: buildings do not perform as predicted or ranked within accreditation procedures. ${ }^{18}$ As regarded within an engineering approach it is possible to state that a large portion of the gap is due to lack of post-occupancy evaluation. ${ }^{19}$ Yet, research on performance gap points out another significant aspect to be addressed; such a gap is related to disregarding the social and behavioral aspects in sustainable architecture and perceiving it solely as an engineering problem. ${ }^{20}$ This gap is partly due to the contested nature of sustainability, extensively discussed by Guy and Farmer, ${ }^{21}$

16. Murray and Cotgrave, "Sustainability literacy: the future paradigm for construction education?" 7-23.

17. Fatima Ghani, "Issues in Sustainable Architecture and Possible Solutions," International Journal of Civil \& Environmental Engineering 12-01 (2012): 21-24.

18. Anna Carolina Menezes et al., "Predicted vs. actual energy performance of nondomestic buildings: Using post-occupancy evaluation data to reduce the performance gap," Applied Energy 97 (2012): 355-364, doi: http://doi.acm.org/10.1016/j.apenergy.2011.11.075.

19. Pieter De Wilde, "The gap between predicted and measured energy performance of buildings: A framework for investigation," Automation in Construction 41 (2014): 40-49, doi: http://doi.acm.org/10.1016/j.autcon.2014.02.009.

20. Altomonte, Rutherford and Wilson, "Mapping the Way Forward: Education for Sustainability in Architecture and Urban Design," 143-154.

21. Guy and Farmer, "Reinterpreting Sustainable Architecture: The Place of Technology," 140-148. 
and is a significant reason for the underestimation of the concept in the production of the built environment.

Besides the insufficiency to address sustainability thoroughly in the production of the built environment, there is a terminological shift that defines the supremacy of the quantifiable. Immediately after the architect's design and drawing processes are completed, construction becomes the main source of terminology to define the architectural work. Therefore, sustainability in architecture is often discussed within technological and engineering advances related to construction, where quantifiable aspects are manifested with parameters. As a result of the multidimensional nature of sustainability, concepts that are challenging to assess (such as the effects of occupants on energy consumption, aspects that are related to health, comfort and productivity of occupants) are overlooked, with a reflex to quantify benefits in order to rapidly indicate a return for economic recognition. Therefore, the design becoming means of construction and sustainable architecture measures that need to be quantified cause a shift in the perception of sustainability from a holistic concept to an assessable technological fix. Quite complementary, Henning $^{22}$ suggests that transferring sustainable technologies from drawing board or marketing facilities to the space is related to "experience, habits, and ways of thinking among a certain group of people", not only the economic impulses. When considered within this quantification-oriented pragmatic approach of the construction practice, this statement might help to point out a lack of responsiveness regarding the occupants of the built environment, and as well with the qualitative aspects of sustainable architecture.

Discussing merely a segment of the contrasts in the perception and application of sustainability concerns for the built environment, it is possible to say that a thorough understanding seems unlikely in near future, where the trending skills of the construction sector overshadow other aspects of sustainable architecture. Therefore, it is significant to turn the look towards architecture education, which fails to provide alumnae who are capable of evaluating all aspects of sustainability for the future benefit of the built environment. $^{23}$

\section{Sustainability in Architectural Education}

Paramount to the discussion of the 'integrity' between sustainability and architecture is to discuss how the concepts of sustainability are considered in architectural education. Integrating sustainability within education has been an increasing focus over the last decades, since the Brundtland Report's criticism towards the education systems on the method of teaching concepts of

22. Annette Henning, "Equal couples in equal houses," in Sustainable Architectures: Cultures and Natures in Europe and North America, ed. Simon Guy and Steven A. Moore (New York: Spon Press, Taylor \& Francis Group, 2005), 89-104.

23. Altomonte, Rutherford and Wilson, "Mapping the Way Forward: Education for Sustainability in Architecture and Urban Design," 143-154. 
sustainability. ${ }^{24}$ In order to ensure sustainability in the built environment, the architecture curriculum should be considered of high importance in supporting the profession. However, the barriers to integrate sustainability into curricula still exist and are due to an array of reasons, which originate from the lack of interest, awareness, compatibility in knowledge, and persistence on defining an ultimate method of teaching sustainability. ${ }^{25,26}$

It is important to stress that almost all architecture schools have courses dedicated to environmentally sensitive design in their curricula. ${ }^{27}$ Notwithstanding, most schools strive for the methods to teach sustainable architecture, with a concern whether the profession is facing the risk to be dominated by engineering aspects and the education system would end up having alumnae acting as 'whole building engineers'. ${ }^{28}$ In order to elaborate such a drawback, one of the main identifications to be made is whether the architectural schools are a medium for job training or they should have the notion to deliver a way of thinking. As the design courses and the rationale behind architectural design approaches are considered, it is possible to assert that the notion of delivering a way of thinking is actually the core of architectural education. However, this notion nourishes a perception that the architecture curriculum, strongly bound to aesthetics and social aspects in design and theory and that has developed a 'rationality criticism combined with nature romanticism and technology skepticism', ${ }^{29}$ has not much to do with the quantifiable aspects of sustainability. Correspondingly, a study by Frederick ${ }^{30}$ demonstrates that 'architecture students identified themselves as, significantly more interested in architecture and design than sustainability and engineering'.

Further criticism that might be helpful to divulge the alienation of architectural education from positive sciences is quoted by Guy and Moore ${ }^{31}$ as follows: "Modern technology, argued Heidegger, tends to enframe or limit our understanding of (architectural) phenomena to narrow categories of quantitative performance, thus 'concealing' or 'challenging' the validity of qualitative meanings". The criticism is comprehensible when the nature of

24. Paola Schmitt Figueiró and Emmanuel Raufflet, "Sustainability in higher education: a systematic review with focus on management education," Journal of Cleaner Production 106 (2015): 22-33, doi: http://bit.ly/1mStOhe.

25. Guy and Farmer, "Reinterpreting Sustainable Architecture: The Place of Technology," 140-148.

26. Altomonte, "Environmental Education for Sustainable Architecture," 12-21.

27. Chad Paul Frederick, "Curriculum Improvement in Education for Sustainable Development: Measuring Learning Outcomes in an Introductory Urban Planning Course," Master's Thesis (Arizona State University, 2012).

28. Hattie Hartman, "Is Sustainability Just Another "Ism"?" Architectural Design April, (2012): 136-140, doi: http://doi.acm.org/10.1002/ad.1444.

29. Martina Keitsch, "Sustainable Design: A Brief Appraisal of its Main Concepts," Sustainable Development 20 (2012): 180-188, doi: http://doi.acm.org/10.1002/sd.1534.

30. Frederick, "Curriculum Improvement."

31. Simon Guy and Steven A. Moore, "Reflections and Engagement: Towards Pluralists Practices of Sustainable Architecture," in Sustainable Architectures: Cultures and Natures in Europe and North America, ed. Simon Guy and Steven A. Moore (New York: Spon Press, Taylor \& Francis Group, 2005), 221-239. 
architecture is solely considered as design issues and theoretical background, and vice versa. Architects tend to distance themselves from the quantitative aspects of the discipline and strengthen the controversy within it, when architecture is perceived as a form of creative composition. To expand the argument further, it is possible to assert that architects, creatively cultivated in integrating different layers (concept, spatial quality, accessibility, utility etc.) of design requirements through multiple decisions, commonly prefer a more situated approach that fulfills theoretical, aesthetical and functional aspects of the design and leaves environmental considerations (e.g. sustainable add-on technologies) to engineers, who are task- and solution-oriented professionals. ${ }^{32}$ Hence, the design of buildings becomes partly in control of architects and partly in control of engineers, who are prepared to introduce the latest technology / service in selection of materials, environmental systems etc.

Hartman ${ }^{33}$ puts an emphasis on the "dismissive attitude of architectural historians -and the profession itself - towards the environmental aspects of architecture" as underlined by Banham: "A vast range of historical topics extremely relevant to the development of architecture is neither taught nor mentioned in many schools of architecture... Mechanical environmental controls are the most obviously and spectacularly important, ... yet they are the least studied." Banham ${ }^{34}$ argues that works and opinions of other disciplines, mainly those related to building services engineering, were part of architectural education as little as possible, hence the control of technology oriented environmental measures have largely passed to building engineers/consultants. On one hand, as the building engineers and consultants continued to introduce new technologies within the building, new problems (e.g. poor indoor air quality due to air tightness) emerged and were solved by new technological fixes (e.g. mechanical ventilation). On the other hand, architects who have distanced themselves from the engineering-driven approaches have in turn thrived to deal with problems regarding sustainability through using traditional construction methods and environmentally responsive design decisions. ${ }^{35}$ However, given the fact that architectural design is a precise composition of creativity, scientific knowledge, technology, social and environmental domains, architects have the responsibility to have enough background knowledge to guide the interdisciplinary design decisions related to sustainability. Otherwise, a knowledge gap emerges and architectural education fails to integrate even the environmental design decisions inherent in the history of architecture.

On one hand, it is possible to argue that the emphasis on the "energy efficient design' in the last decades widened the gap between the technological and theoretical aspects of architectural education. On the other hand, 'energy efficiency' is proven to be a vital aspect for the sustainable built environment

32. Reyner Banham, The Architecture of the Well Tempered Environment, $2^{\text {nd }}$ edition (Chicago: The University of Chicago Press, 1984).

33. Hartman, "Is Sustainability Just Another "Ism"?" 136-140.

34. Banham, The Architecture of The Architecture of the Well Tempered Environment.

35. Ibid. 
and is an outcome of a process that involves multidisciplinary approaches. ${ }^{36}$ Given these contrasting point of views, it is possible to assert that architectural education needs to embrace the fact that sustainability and its concerns are 'related' to architecture (predominantly with an emphasis on sustainable technologies, which are mainly regarded as engineering approaches). In addition, the subjects should not be considered as the responsibility of engineers who are specialized in 'whole building' studies. A pluralist approach that acknowledges environmental design decisions (i.e. passive / climatic design), traditional methods that can be tracked through history of architecture, ${ }^{37}$ and engineering-driven and building integrated sustainable systems would become much more efficient in addressing the concepts of sustainability without fundamentally excluding different aspects of the concept. In this framework, it is important to communicate the notion of sustainability to students of architecture since they would become professionals in the architectural practice. The only way to bridge the above-mentioned knowledge gap is an in-depth understanding of sustainability concepts and their relation to the architecture discipline, with a responsive curriculum based on pedagogies that combine technical and holistic issues of sustainability. ${ }^{38}$

\section{The Responsive Architecture Curriculum}

Architects' statements often involve the accent to 'design the future' and as quoted in Wright, ${ }^{39}$ Boyerd and Mitgangassert, "Architects and architecture educators assume a leadership role in preserving the environment and planet's resources."A discipline with such priorities needs a substantiation of the claim with continuous rethinking and questioning of related concepts within architectural practice, education and their effects on the society. ${ }^{40}$

As identified in previous sections, sustainable architecture is often perceived as the governing title for energy related issues within the built environment. This misperception is the main barrier against the integration of the concept in the architectural education. Given the fact that elaboration of sustainability appears to be the subject of universally applied assessment methods (such as BREEAM, ${ }^{41}$ LEED). ${ }^{42}$ These methods commonly operate

36. S. Manu et al., "Architectural Curriculum Enhancement for Promoting Sustainable Built Environment in India," pres. at The ACEEE Summer Study on Energy Efficiency in Buildings (Pacific Grove, CA, 15-20 August 2010), 196-212.

37. Banham, The Architecture of The Architecture of the Well Tempered Environment.

38. Altomonte, Rutherford and Wilson, "Mapping the Way Forward: Education for Sustainability in Architecture and Urban Design," 143-154.

39. James Wright, "Introducing sustainability into the architecture curriculum in the United States," International Journal of Sustainability in Higher Education 4-2 (2003): 100105, doi: http://doi.acm.org/10.1108/14676370310467131.

40. Serap Durmus, "Change and Transformation in Architecture: On the Concept of Zeitgeist," Global Built Environment Review: A Journal for Architecture, Planning, Development and The Environment (GBER) 8 (2012): 22-36.

41. BREEAM (Building Research Establishment Environmental Assessment Methodology). For more information: http://www.breeam.org. 
with the tendency to take the building as a matter of scientific analysis and as a result alienate 'green' or 'sustainable' buildings ${ }^{43}$ from strong aspects as design considerations and theoretical backgrounds. Hence, the supremacy of sustainable technologies over concepts such as locality, minimal use of resources, environmental design approaches might result in stereotype sustainability measures within the built environment, which aren't incorporated in the aesthetics of design, and are solely technological fixes. ${ }^{44}$

In this scope, it is necessary to incorporate essential changes to architectural education, which would be helpful to transform the curricular understanding of the concept within architecture discipline and to instigate a response in the practice of the built environment towards a holistic sustainability approach. When buildings are considered as a design outcome, which continuously transforms the social and environmental contexts, and which defines the interaction of its occupants with the building and each other, the need for such a holistic approach becomes more clear. Intrinsic to the classical model of sustainability, the intersecting set of environmental, economic, social and technological concerns, ${ }^{45,46}$ adopting a holistic approach has the potential to introduce an enhanced architectural pedagogy that encompasses architectural design considerations, built environment, social, cultural and political contexts, environmental concerns, economic and technological considerations and the occupants (Figure 1).

42. LEED (Leadership in Energy \& Environmental Design). For more information: http://leed.usgbc.org.

43. Graham Farmer and Simon Guy, "Making morality: sustainable architecture and the pragmatic imagination," Building Research \& Information 38-4 (2010): 368-378, doi: http://doi.acm.org/10.1080/09613218.2010.482236.

44. Keitsch, "Sustainable Design: A Brief Appraisal of its Main Concepts," 180-188.

45. Räthzel and Uzzell, "Transformative environmental education: a collective rehearsal for reality," 263-277.

46. E. Pappas, O. Pierrakos and R. Nagel, "Using Bloom's Taxonomy to teach sustainability in multiple contexts," Journal of Cleaner Production 48 (2013): 54-64, doi: http://dx.doi.org/10.1016/j.jclepro.2012.09.039. 


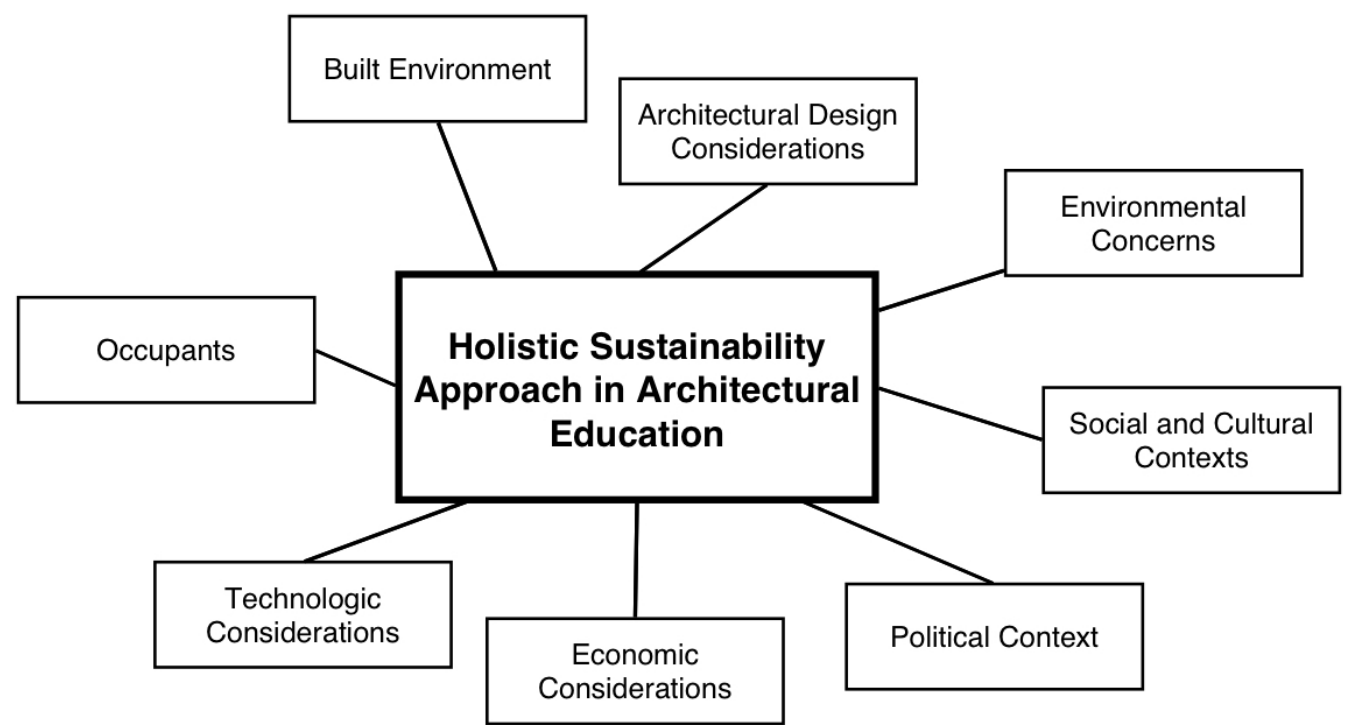

Figure 1. Considerations that Compose a Holistic Sustainability Approach in Architectural Education

In order to suggest the means to holistically incorporate sustainability concepts in architectural education, the barriers need to be addressed first. The barriers could be summarized as problems involving faculty structure, regarding sustainability as a postgraduate subject, regarding sustainability as an area of specialization and considering sustainable architecture as a separate track within architecture curriculum. Possible reasons to disregard a responsive architecture curriculum that covers sustainability as an underlying core concept could stem from lack of faculty members related to the concepts of sustainability, considering that it is not feasible to make a change in the curriculum, regarding the concept as in significant, accepting that students are not interested in the subject, strength to maintain the current status of the curriculum, limited time frame of faculty members, multidisciplinary aspects of sustainability research, and lack of awareness. ${ }^{47,48,49}$

Commonly, concepts within sustainability are considered as postgraduate subjects, given the course load and diverse specialization of faculty $\operatorname{staff}^{50}$. This perception is precarious, since majority of the alumnae of undergraduate architecture programs prefer to work within practice, actively contributing the production of the built environment. On the contrary, the majority of postgraduate students tend to continue their expertise within the academia. In this

47. Burcin Becerik-Gerber, David J. Gerber and Kihong Ku, "The pace of technological innovation in architecture, engineering, and construction education: Integrating recent trends into the curricula," Journal of Information Technology in Construction 16 (2011): 411-432.

48. Lidgren, Rodhe and Don Huisingh, "A systemic approach to incorporate sustainability into university courses and curricula," 797-809.

49. Kim Ceulemans and Marijke de Prins, "Teacher's manual and method for SD integration in curricula," Journal of Cleaner Production 18 (2010): 645-651, doi: http://doi. acm.org/10.1016/j.jclepro.2009.09.014.

50. Altomonte, Rutherford, and Wilson, "Mapping the Way Forward: Education for Sustainability in Architecture and Urban Design," 143-154. 
regard, it is evident that the discourses and technologies inherent in sustainable architecture face the risk of staying in a theoretical sphere. Therefore, in undergraduate studies a firm understanding of sustainability, as a way of thinking instead of perceiving it as a trend is of utmost importance and would be useful to let the students be able to deliver the fundamentals of sustainability into the built environment practice. As Jennings ${ }^{51}$ argues it is important to be concerned about the environmental problems and to address them as urgent, yet only few comprehend the basic causes behind the problems.

Furthermore, the idea of specialization is essentially contrary to the nature of sustainable architecture, since it covers a wide range of decision-making in different scales (e.g. from massing to urban scale decisions). Therefore, as curricula propose specialization, architecture students locate themselves in a track of interest (e.g. design, technology, history, etc.). This interest in a specialization of architectural profession is natural however; it does not mean that the students might alienate themselves from the contents of other tracks. Comparable to selecting a major and sufficiency required in minor tracks during undergraduate studies, sustainability and its diverse approaches need to be reconciled within architecture education as well. Hence, the first idea could be adopting sustainability as an additional track within the curriculum. However, a sustainable built environment requires a holistic understanding of the approaches within the sustainability concept (Figure 1), in relation to the diversity of tracks within architecture curriculum. Therefore, faculty members who teach architecture need to undertake the responsibility to introduce to the students the literacy of sustainability, both with the qualitative and quantitative aspects of it.

As John, Clements-Croome and Jeronimidis ${ }^{52}$ assert, "the natural world has an immense amount to tell us about how to achieve sustainability" and as Hartman $^{53}$ puts forward, "sustainable design does not happen by itself". These statements could be understood as the main references for an architecture curriculum, which appropriately incorporated concepts of sustainability. The first statement actually propagates an understanding of the sustainability knowledge, not in the form of mere information, but with strong conceptualization opportunities within the natural world. The second statement, on the other hand, indicates that in order to integrate this knowledge into implementation to interpret concepts of sustainability within architectural design, an educated approach is fundamental. ${ }^{54,55}$ Based on these two statements, the framework for a holistic sustainability approach in architectural

51. Jennings, "New directions in renewable energy education," 435-439.

52. Godfaurd John, Derek Clements-Croome and George Jeronimidis, "Sustainable building solutions: a review oflessons from the natural world," Building and Environment 40 (2005): 319-328, doi: http://bit.ly/1RWzuDL.

53. Hartman, "Is Sustainability Just Another "Ism”?" 136-140.

54. John Blewitt, "Introduction," in The Sustainability Curriculum: The Challenge for Higher Education, ed. J. Blewitt and C. Cullingford (Earthscan, 2004), 1-9.

55. Satish Kumar, Shruti Narayan, Sanyogita Manu and Tulsyan Ankur, "Role of Architectural Education in Promoting Sustainable Built Environment," New Delhi, India, 2010 . 
education would be promising as long as the subject is regarded as knowledge instead of information and as the faculty members presents a mind shift towards perceiving sustainability as a concept, including social, cultural, and technological aspects. ${ }^{56}$ As Savageau ${ }^{57}$ suggests that long term behavioral change is limited in teaching sustainability and to overcome such limitation there is a certain necessity to alter the behavior of faculty members and students. Thus, a comprehensive progression for conceptualization and implementation of sustainability in architecture curriculum would become evident, due to the responsive attitude of faculty members, students, and professionals within the built environment practice. ${ }^{58}$

A responsive architecture curriculum therefore should aim to establish a life-long learning and implementation of sustainability concepts. To achieve such an aim, the first step is to embrace sustainable architecture as a priority and recognize that sustainable design is a core issue of architectural education. ${ }^{59}$ As Wright quoted Fraker, ${ }^{60}$ this could be only possible by designing a responsive curriculum, which provides depth within the knowledge and choice beyond introductory courses. In addition, the necessity to establish a way of thinking among architecture students and enough understanding on the notions of sustainability and sustainable measures within the built environment indicate the need to focus on providing a responsive curriculum that delivers sustainability as an inseparable concept from all inherent aspects of architecture. Given the fact that most schools of architecture have a design approach that has become normative, it would only be possible to actualize a responsive curriculum through defining its steps appropriately. Prior to structuring the curriculum, faculty members might need to work on consensual and conflicting issues. Figure 2 presents a possible approach for instigating work on a responsive curriculum, through which each faculty member could have the chance to participate and integrate concepts of sustainability according to their potentials and specializations. The first two steps of the approach in Figure 2 indeed aim to bring forward the potentials and ideas through a discussion based on the composition and standpoint of faculty members with regard to their views on sustainability. Teaching sustainable architecture concepts through a responsive curriculum might either be accepted or rejected as a result of this discussion. Accepting the responsive curriculum would require identification of the variety of approaches in sustainable architecture and the definition of their relation to disciplinary tracks of architecture (e.g. design, history and theory, building science, computer aided

56. Altomonte, Rutherford, and Wilson, "Mapping the Way Forward: Education for Sustainability in Architecture and Urban Design," 143-154.

57. Ann E.Savageau, "Let's get personal: making sustainability tangible to students," International Journal of Sustainability in Higher Education 14-1 (2013): 15-24, doi: http://doi. acm.org/10.1108/14676371311288921.

58. Kumar, Narayan, Manu and Ankur, "Role of Architectural Education in Promoting Sustainable Built Environment."

59. Wright, "Introducing sustainability into the architecture curriculum in the United States," 100-105.

60. Ibid. 
design). As a next step, the means to provide necessary background information on concepts of sustainable architecture as supplement to course tracks, develop responsive approaches to integrate sustainability concept within the curriculum, and establish links between the course track for the dissemination of sustainability knowledge could be formulated to facilitate addressing sustainability holistically. Hence, all tracks within architecture would be able to ensure that they associate their discourse or content with appropriate emphases on sustainability. Due to this approach, the abstract knowledge would be internalized beyond becoming a notion of 'mere information' and integrating sustainability in architecture curriculum would have the chance to become more interdisciplinary. ${ }^{61}$

This approach would then also be useful to remove the criticism that integrating sustainability into the design curriculum would cause the engineering and technology aspects to exceed the intrinsic artistic and humanities embedded in the discipline and vice versa. In order to fully recover architecture education from such an impasse there is an undeniable necessity to integrate sustainability concerns to all courses within a discussion-based approach and evidence-based learning. Both the discussion-based approach and evidence-based learning, could be operated as two main approaches that initiate the responsive nature of the curriculum, since the interaction between the parts of curriculum could provide a way of teaching through conceptualization, coordination and execution. Consequently, along with the prominence of creativity, skill and intuition of architecture students, an accent could be placed on diverse considerations such as technology, environment, economy, sociology and politics in order to emphasize that the work of an architect should critically address issues related to the context, built environment and social, cultural and humane aspects. ${ }^{62}$

61. Blewitt, "Introduction," 1-9.

62. Ashraf Salama, "Skill-based / knowledge -based architectural pedagogies: An argument for creating humane environments," pres. at 7th Intl Conference on Humane Habiate-ICHH-05. (Mumbai, India: The International Association of Humane Habitat IAHH Rizvi College of Architecture, 2005). 


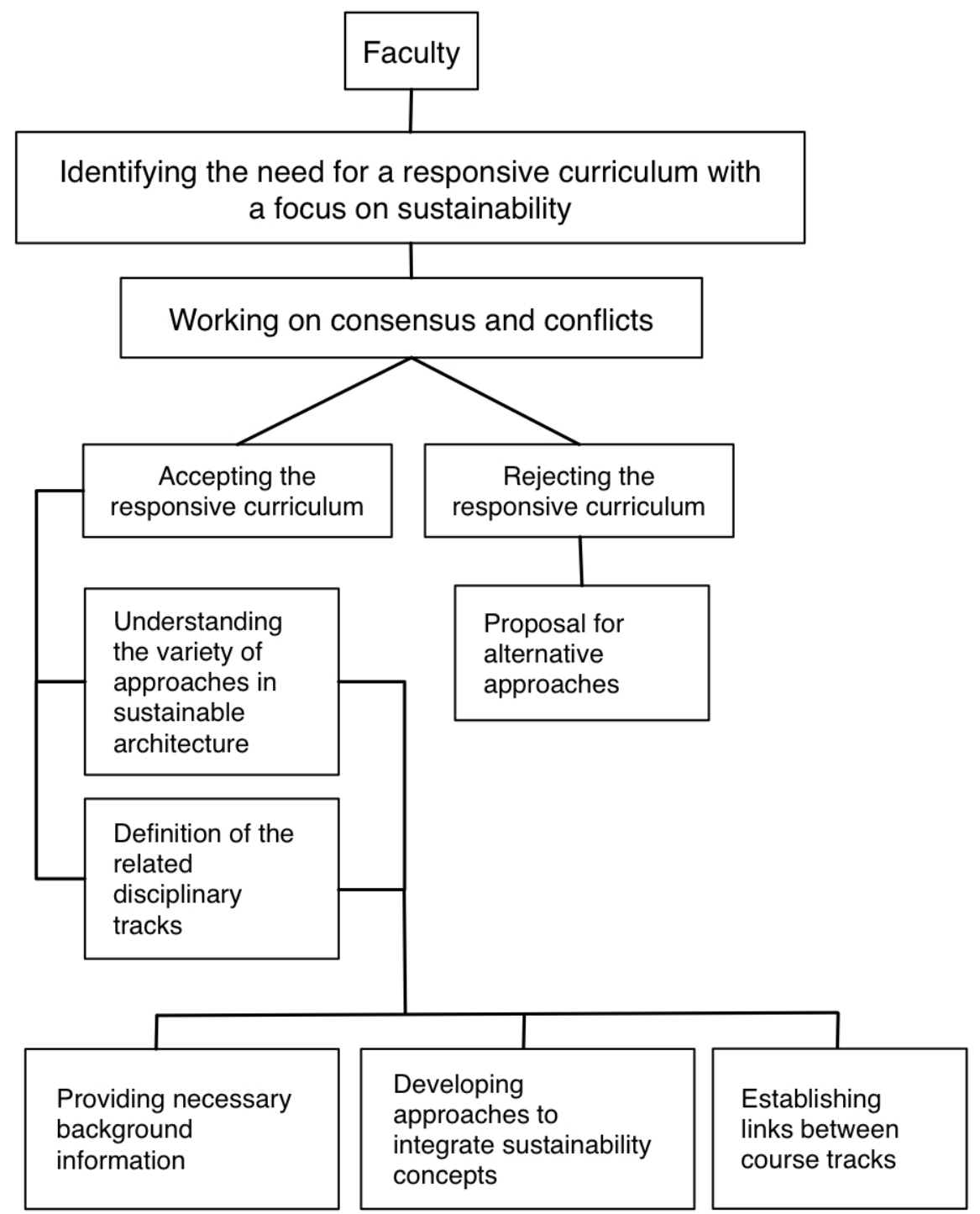

Figure 2. Steps for Adopting a Responsive Curriculum with a Focus on Sustainability

In order to elucidate the discussion-based approach, initially it is necessary to introduce the concepts as a way of thinking. Relating the concepts to life practices would be more effective in increasing the interest and awareness towards the concepts of sustainability. For instance, in order to discuss the 'greenness' of building materials, discussing students' recycling habits in the daily life could be cordial to put an emphasis on the importance of using building materials that are recyclable. This approach is significant since it is directly related to lifestyle and perception towards the environment. As the students internalize such an opinion and start changing habits in daily life it would be more promising if they develop a level of awareness as designers, who decide on the built environment. A developing consciousness, in many cases, is more important than simply stating stereotype statistical information during lectures. 
An additional paradigm in integrating sustainability in the architecture curriculum could be to enhance the discussion-based approaches with evidence-based learning. Once the students grasp the relationship between design decisions and sustainable measures, the theoretical knowledge could easily be coupled with evidence. For instance, measuring the indoor thermal profiles of students' accommodation and correlating the data with energy bills could easily initiate an understanding of the occupant comfort on energy performance. In situations when evidence-based learning methodology is not applicable courses that integrate simple simulation tools, which facilitate rapid outcomes, might be useful to cultivate students' perception on different design decisions and their effects on sustainability. Such an approach could be realized through integrating supplementary courses, which do not directly influence the design course, yet gives the student feedback on the possible environmental effects of design decisions.

The above-mentioned explanations for the proposed discussion-based approach and evidence-based learning strategies might raise questions on how to establish the links between two tools of the responsive curriculum and the course tracks of the architecture. In order to clarify that, Table 1 presents the strategies to integrate sustainability concepts in different course tracks of architecture. The strategies presented in Table 1 could be enhanced, transformed or altered according to the architectural education tradition of a particular faculty. Hence, maintaining the effort to formulate the curriculum around a discussion-based approach and evidence-based learning strategies and providing links between course tracks would provide a thorough understanding of sustainability concepts and at a certain level would still be effective regarding the sustainability of the built environment.

In summary, to stimulate awareness and high-interest in sustainable architecture, the weekly curriculum of each course should take the responsibility to address discussions to trigger a critical understanding of the concept. Even a narrative of sustainability concepts during discussion-based course hours and use of analogies such as life-cycle thinking in selecting a shopping bag, recycling habits, modeling or measuring real world phenomena or understanding the concepts through computer models and assessing effect of sustainable measures could be used to stimulate interest and awareness. Hence, the notion of concepts of sustainability would become internalized and could be used as fundamental skills which provide the ability to establish methodological thinking when there is the need to develop a holistic sustainable architectural approach with different weights of its constituents (context, social construct, energy performance, investment, indoor environmental health etc.). Thus, without underestimating any of the qualitative and quantitative assessments for a particular case, it would be possible for future architects to provide the anticipation towards the utilization of a flexible approach in fully addressing sustainability of the built environment. 
Table 1. Strategies to Integrate Sustainability Concepts in Different Course Tracks of Architecture Curriculum

\begin{tabular}{|c|c|c|}
\hline \multirow{2}{*}{$\begin{array}{l}\text { Course } \\
\text { Tracks }\end{array}$} & \multicolumn{2}{|c|}{ Strategies to Integrate Sustainability Concepts in Different Course Tracks of Architecture Curriculum } \\
\hline & Discussion-Based Approach & Evidence-Based Learning \\
\hline $\begin{array}{l}\text { History and } \\
\text { Theory }\end{array}$ & $\begin{array}{l}\text { - Discussing the history of mechanization of environmental } \\
\text { management (Banham 1987) } \\
\text { - Discussing environmentally sensitive traditional building } \\
\text { principles as a part of history courses (Banham 1987) } \\
\text { - Discussing certain periods' economic, political, environmental } \\
\text { social contexts and their relation to architectural movements }\end{array}$ & $\begin{array}{l}\text { Asking students to identify sustainability principles for the discussed } \\
\text { examples through sketches and drawings (in coordination with } \\
\text { building science and computer aided design courses) } \\
\text { Endorsing students to critically assess the changes in building } \\
\text { construction through the course of history and theory of architecture. }\end{array}$ \\
\hline $\begin{array}{l}\text { Architectural } \\
\text { Design }\end{array}$ & $\begin{array}{l}\text { - Discussing the necessity and conflicts in including sustainability } \\
\text { knowledge acquired from other course tracks within the design } \\
\text { process } \\
\text { - Discussing the occupant and occupant needs as essential concepts } \\
\text { - Discussing social, cultural and economic aspects and their } \\
\text { relationship with sustainability (along with discussions in history } \\
\text { and theory courses) }\end{array}$ & $\begin{array}{l}\text { - Endorsing students to conduct field studies to collect qualitative data } \\
\text { regarding the occupants' perception on diverse subjects such as } \\
\text { sustainability, comfort, health, energy and resource use, spatial use, } \\
\text { social and environmental aspects of the built environment, etc. } \\
\text { - Formulating short-term design problems that allow the comparison } \\
\text { between different design decisions and their effects on environment, } \\
\text { resource use and other targeted sustainability concepts (in coordination } \\
\text { with building science and computer aided design courses) }\end{array}$ \\
\hline $\begin{array}{l}\text { Building } \\
\text { Science }\end{array}$ & $\begin{array}{l}\text { - Discussing resources in terms of environmental degradation and } \\
\text { act of building, with certain emphasis to political, economic and } \\
\text { technological contexts } \\
\text { - Discussing the main denominators behind material selection in } \\
\text { history of architecture and current context } \\
\text { - Discussing sustainability goals other than green roofs, } \\
\text { photovoltaic facades, building integrated wind tribunes etc. }\end{array}$ & $\begin{array}{l}\text { - Posing research questions regarding sustainability measures } \\
\text { - Data collection and understanding concepts and tools to evaluate the } \\
\text { collected data } \\
\text { - Drawing conclusions on the possible effects of sustainability measures } \\
\text { - Interpreting drawn conclusions for further design problems (in } \\
\text { coordination with building science and computer aided design courses) }\end{array}$ \\
\hline $\begin{array}{l}\text { Computer } \\
\text { Aided Design }\end{array}$ & $\begin{array}{l}\text { - Discussing the capabilities of computer aided tools designed to } \\
\text { evaluate sustainability measures, understanding their strength and } \\
\text { weaknesses } \\
\text { - Acknowledging the beneficial aspects of the tools and discussing } \\
\text { whether these tools are of ultimate priority in sustainability } \\
\text { assessment }\end{array}$ & $\begin{array}{l}\text { - Delivering the basic understanding of computer aided tools to evaluate } \\
\text { sustainability measures in building design (in coordination with } \\
\text { building science courses) } \\
\text { - Relating above-mentioned tools with assignments from building } \\
\text { science courses or architectural design problems }\end{array}$ \\
\hline
\end{tabular}


Naturally there is no single path to follow in establishing such responsive curriculum, since there can be no universal pedagogy that covers the notion of teaching/learning architecture. However, integrating environmental, technological, cultural and human centered approaches to architecture curriculum could be considered within the composition and tradition of each faculty. In order to achieve a responsive architecture curriculum, understanding the strengths of faculty members in sustainability concepts, providing exchange of views, and facilitating training opportunities might result in a consensus in teaching strategies to increase the interest and awareness of students. Consequently, the revisions to the curriculum, by integrating a discussionbased approach and evidence-based learning that cover a social and technological understanding of sustainability in the built environment, should be accomplished. Due to the precision in such interaction and continuous crossreferencing between courses of different tracks would be useful for the comprehension of students on the notion of sustainable architecture.

\section{Conclusions}

It is evident that the lack of thorough understanding of sustainability in architectural education is strongly influential on the architecture profession and the regulations designed to achieve a sustainable built environment. Considering the idea of teaching sustainability as the ultimate goal in architectural education might provide ineffective results since the knowledge gap between the quantitative and qualitative approaches might not be bridged effectively.

Given the discussions above, it is futile to introduce a stereotypical curriculum to stimulate sustainable architecture education. Architectural education, possessing a valuable diversity of cultural, social, aesthetic and technological concepts, should embrace a flexible approach that aims to introduce the notion of sustainability as a way of understanding the relationship between the built, natural, and contextual environments. This flexibility could only be achieved by providing a responsive curriculum that integrates sustainability concerns to all courses within discussion-based approach and evidence-based learning.

This paper intended to provide a basis for discussion for future endeavor to integrate sustainability into the architecture curriculum with a responsive method. Future research might cover a detailed survey with professionals, educators and students to reveal their approach and perception towards sustainability as a holistic concept and encourage diversity of approaches to be integrated within architectural curricula.

\section{Bibliography}

Altomonte, Sergio. "Environmental Education for Sustainable Architecture." Review of European Studies 1-2 (2009): 12-21. doi: http://bit.ly/1Q54ehp. 
Altomonte, Sergio, Peter Rutherford and Robin Wilson. "Mapping the Way Forward: Education for Sustainability in Architecture and Urban Design." Corporate Social Responsibility and Environmental Management 21 (2014): 143-154. doi: http://doi.acm.org/10.1002/csr.1311.

Banham, Reyner. The Architecture of the Well Tempered Environment. Chicago: The University of Chicago Press; $2^{\text {nd }}$ Edition, 1984.

Becerik-Gerber, Burcin, David J. Gerber and Kihong Ku. "The pace of technological innovation in architecture, engineering, and construction education: Integrating recent trends into the curricula." Journal of Information Technology in Construction 16 (2011): 411-432.

Blewitt, John. 2004. "Introduction.” In The Sustainability Curriculum: The Challenge for Higher Education, 1-9. Edited by John Blewitt and Cedric Cullingford. Earthscan, 2004.

Callicott, J. Baird and Karen Mumford. "Ecological Sustainability as a Conservation Concept." Conservation Biology 11-1 (1997): 32-40. doi: http://doi.acm.org/10.1046/j.1523-1739.1997.95468.x.

Ceulemans, K. and M. De Prins. "Teacher's manual and method for SD integration in curricula." Journal of Cleaner Production 18 (2010): 645-651. doi:http://doi.acm.org/10.1016/j.jclepro.2009.09.014.

De Wilde, Pieter. "The gap between predicted and measured energy performance of buildings: A framework for investigation." Automation in Construction 41 (2014): 40-49. doi: http://doi.acm.org/10.1016/j.autcon.2014.02.009.

Durmus, Serap. "Change and Transformation in Architecture: On the Concept of Zeitgeist." Global Built Environment Review: A Journal for Architecture, Planning, Development and The Environment (GBER) 8 (2012): 22-36.

Farmer, Graham and Simon Guy. "Making morality: sustainable architecture and the pragmatic imagination." Building Research \& Information 38-4 (2010): 368-378. doi: http://doi.acm.org/10.1080/09613218.2010.482236.

Figueiró, Paola Schmitt and Emmanuel Raufflet "Sustainability in higher education: a systematic review with focus on management education." Journal of Cleaner Production 106 (2015): 22-33. doi: http://bit.ly/1mStOhe.

Frederick, C. P. Curriculum Improvement in Education for Sustainable Development: Measuring Learning Outcomes in an Introductory Urban Planning Course. Master's Thesis, Arizona State University, 2012.

Ghani, Fatima. "Issues in Sustainable Architecture and Possible Solutions." International Journal of Civil \& Environmental Engineering 12, no. 1 (2012): 2124.

Guy, Simon and Graham Farmer. "Reinterpreting Sustainable Architecture: The Place of Technology." Journal of Architectural Education 54-3 (2001): 140-148. doi: http://doi.acm.org/10.1162/10464880152632451.

Guy, Simon and Steven A. Moore. "Reflections and Engagement: Towards Pluralists Practices of Sustainable Architecture." In Sustainable Architectures: Cultures and Natures in Europe and North America, 221-239. Edited by Simon Guy and Steven A. Moore. New York: Spon Press, Taylor \& Francis Group, 2005.

Hartman, Hattie. "Is Sustainability Just Another "Ism"?" Architectural Design April (2012): 136-140. doi: http://doi.acm.org/10.1002/ad.1444.

Henning, A. 2005. "Equal couples in equal houses." In Sustainable Architectures: Cultures and Natures in Europe and North America. Edited by Simon Guy and Steven A. Moore, 89-104. New York: Spon Press, Taylor \& Francis Group, 2005.

Jennings, Philip. "New directions in renewable energy education." Renewable Energy 34 (2009): 435-439. doi: http://doi.acm.org/10.1016/j.renene.2008.05.005. 
John, Godfaurd, Derek Clements-Croome and George Jeronimidis "Sustainable building solutions: A review of lessons from the natural world." Building and Environment 40 (2005): 319-328. doi: http://bit.ly/1RWzuDL.

Keitsch, Martina. "Sustainable Design: A Brief Appraisal of its Main Concepts." Sustainable Development 20 (2012): 180-188. doi: http://doi.acm.org/10.1002/sd.1534.

Kumar, Satish, Shruti Narayan, Sanyogita Manu and Tulsyan Ankur. "Role of Architectural Education in Promoting Sustainable Built Environment." New Delhi, India: 2010.

Lidgren, Alexander, Hakan Rodhe and Don Huisingh. "A systemic approach to incorporate sustainability into university courses and curricula." Journal of Cleaner Production 14 (2006): 797-809. doi: http://bit.ly/1PRLfZG.

Manu, S., A. Bajpai, S. Kumar, S. Narayan and A. Tulsyan. "Architectural Curriculum Enhancement for Promoting Sustainable Built Environment in India." Presented at The ACEEE Summer Study on Energy Efficiency in Buildings, 196-212. Pacific Grove, CA: 15-20 August 2010.

Masseck, T. "Teaching Sustainability through Living Labs in Architecture: The case study of the UPC-LOW3 prototype solar house." Presented at Engineering Education for Sustainable Development. In The proceedings of the EESD13 Conference, 1-9. Cambridge, UK: 2013.

Menezes, Anna Carolina, Andrew Cripps, Dino Bouchlaghem and Richard Buswell. "Predicted vs. actual energy performance of non-domestic buildings: Using postoccupancy evaluation data to reduce the performance gap." Applied Energy 97 (2012): 355-364. doi:http://doi.acm.org/10.1016/j.apenergy.2011.11.075.

Murray, Paul E. and Alison J. Cotgrave. "Sustainability literacy: the future paradigm for construction education?" Structural Survey 25-1, (2007): 7-23. doi: http://doi.acm.org/10.1108/02630800710740949.

Pappas, E., O. Pierrakos and R. Nagel. "Using Bloom's Taxonomy to teach sustainability in multiple contexts." Journal of Cleaner Production 48 (2013): 54-64. doi: http://dx.doi.org/10.1016/j.jclepro.2012.09.039.

Räthzel, Nora and David Uzzell. "Transformative environmental education: a collective rehearsal for reality." Environmental Education Research 15-3, (2009): 263-277. doi: http://dx.doi.org/10.1080/13504620802567015.

Rozema, Jaap G., Alan J. Bond, Matthew Cashmore and Jason Chilvers. "An investigation of environmental and sustainability discourses associated with the substantive purposes of environmental assessment." Environmental Impact Assessment Review 33 (2012): 80-90. doi: http://bit.ly/1TzWvxx.

Salama, Ashraf. "Skill-based / knowledge -based architectural pedagogies: An argument for creating humane environments." Presented at The $7^{\text {th }}$ Intl Conference on Humane Habiate-ICHH-05. Mumbai, India: The International Association of Humane Habitat IAHH Rizvi College of Architecture, 2005.

Savageau, Ann E.. "Let's get personal: making sustainability tangible to students." International Journal of Sustainability in Higher Education 14-1, (2013): 15-24. doi: http://doi.acm.org/10.1108/14676371311288921.

WCED, World Commission on Environment and Development. Our Common Future - Brundtland Report. United Nations Report, Oxford University Press, 1987.

Wright, James. "Introducing sustainability into the architecture curriculum in the United States." International Journal of Sustainability in Higher Education 4-2, (2003): 100-105. DOI= http://doi.acm.org/10.1108/14676370310467131. 
